\title{
SIMONE WEIL. UN GRITO DESDE LA CUEVA DEL SILENCIO
}

\author{
Dennys María Castro Martínez \\ doi:10.11144/Javeriana.uph31-62.swgc
}

\begin{abstract}
RESUMEN
En los últimos años de su corta vida, Simone Weil escribió el ensayo La Ilíada o el poema de la fuerza, un hermoso y lúcido canto a la virtud griega evidenciada en la cruenta guerra de Troya. A partir de allí, y a través de una exploración de su obra, el presente artículo intenta dilucidar el papel de la fuerza como clave para interpretar los fenómenos sociales y las relaciones entre los hombres. Asimismo, pretende comprender el significado y el valor del dolor y del sufrimiento como constitutivos de lo humano; lo que en esta filósofa, cuya vida fue totalmente coherente con su pensamiento y sensibilidad, no es otra cosa que el puro acercamiento a la pureza de lo divino.
\end{abstract}

Palabras clave: Simone Weil; fuerza; dolor; sufrimiento; sacralidad

\footnotetext{
${ }^{*}$ Universidad Metropolitana de Barranquilla, Barranquilla, Colombia.

Recibido: 10.09.13

ACEPTADO: 05.12.13

DISPONIBLE EN LÍNEA: 30.06 .14

Para citar este artículo: Castro Martínez, D.M. (2014). Simone Weil. Un grito desde la cueva del silencio. Universitas Philosophica, 31(62), 169-193. ISSN 0120-5323; ISSN en línea 2346-2426; doi:10.11144/Javeriana.uph31-62.swgc
} 


\title{
SIMONE WEIL. A SCREAM FROM THE CAVE OF SILENCE
}

\author{
Dennys María Castro Martínez
}

\begin{abstract}
In the last years of her short life, Simone Weil wrote the essay: The Iliad or the poem of force, a beautiful and lucid song to the greek virtue made clear during the Trojan War. From this reading, and through the exploration of her work, this article aims to elucidate the role of force as a key to understand the social phenomenon and the relations among human beings. Furthermore, it pretends to grasp the meaning and value of pain and suffering as constituent elements of the human, which according to this philosopher, whose life was absolutely coherent with her thinking and sensitivity, is the purer approach to the pureness of the divine.
\end{abstract}

Key words: Simone Weil; force; pain; suffering; sacredness 
EN PLeNo AUGE DE LOS IDEALES DE LA REVOluCión FRANCESA, entre aquellos que fundamentarían la fe suprema en la razón, Fichte, seguidor de Kant, anunciaba el imperio del yo como un absoluto que se determina a sí mismo, aunque no en forma aislada, sino en relación física y moral con el mundo y con los demás. En cuanto a las cosas, ese yo se afirma con una fe inmediata en la libertad y la independencia del encuentro de sí mismo. Sin embargo, no todos los hombres alcanzan este pleno sentimiento de libertad, pues algunos casi se amalgaman, encuentran su identidad y hasta existen solo con las cosas, hasta el punto de perder su yo cuando éstas, que sustentan su existencia, les son despojadas. En consecuencia, Fichte distingue dos tipos o géneros capitales, como él llama, de hombres: unos, que solo necesitan de la afirmación de su yo y, por tanto, son independientes; otros, cuya fe está puesta en las cosas y no alcanzan la independencia. Mientras que estos últimos estarán al servicio de un sistema que justifica el servilismo y adherirán al dogmatismo, los primeros lucharán por un sistema de libertad y, sin duda, seguirán el idealismo.

En todo caso, la lúcida clasificación que establece Fichte permite acercarse a la siguiente sentencia, lugar de reflexión de los estudiosos de la filosofía desde hace largos años: "Qué clase de filosofía se elige, depende de qué clase de hombre se es". Declaración que pone el acento en la tarea de hacerse humano, que se determina por su ideología y por su sistema de pensamiento, pues "un sistema filosófico no es un ajuar muerto que se puede dejar o tomar, según nos plazca, sino que está animado por el alma del hombre que lo tiene" (Fichte, 1984: 46). En nuestra época, dicha reflexión es retomada por Peter Sloterdijk para discurrir acerca de la relación entre vida y filosofía o, según sus palabras, entre alma y logos, a través de la cual ilustra la innegable diversidad del alma humana, que no se agota en dos tipos, tal como lo proponía Fichte, sino que muestra su carácter inagotable e ilimitado.

La anterior anotación resulta muy útil para la presentación de este tema, en el que la vida y las vivencias de Simone Weil (1909-1943) se confunden o se amalgaman, de tal manera que es inevitable acudir a su biografía para comprender su obra. Las biografías no son expresiones de vidas acabadas en su dimensión biológica, sino testimonios vivos de proyectos inacabados, de sueños inconclusos y de contradicciones no resueltas. Esto toma una especial dimensión de realidad en la corta pero intensa vida de la autora; sin embargo, no pretendo agotar el tema allí, pues son innumerables las alusiones biográficas y las referencias bibliográficas que han puesto de 
relieve su importante lugar en el mundo del pensamiento y las ideas. Antes bien, nos cuidamos de no caer en el error en que incurre la mayoría de sus detractores y que Weil denunciara en una de las más acerbas críticas a un autor, a propósito de la biografía que publicó Otto Rühle sobre Karl Marx. Opinión influenciada por Alain ${ }^{1}$ cuando fue su maestro, que le enseñó a considerar con amor las grandes obras, los grandes hombres y a despreciar las tendenciosas o acomodadas explicaciones psicológicas que no revelan el auténtico valor de la persona ni de su producción.

De la misma manera, atribuirle a las dificultades físicas o emocionales de Weil una relación causal con su obra y su actividad política sería caer en aquello que, de Rhüle, tanto la indignó: endilgarle a Marx que su genial obra fue producto de un carácter orgulloso y luchador que surgió como compensación de un sentimiento de inferioridad, debido almal funcionamiento digestivo que siempre padeció ${ }^{2}$. Esto es, que todo lo que en las acciones o pensamientos humanos tiene valor consiste en una cierta imitación de Dios, según lo sostiene Platón y de acuerdo con lo que hizo Weil, pues impelida por la necesidad de acercarse a la verdad suprema, luchó por sobrepasar sus propios límites, real fuente de toda grandeza. Por ello, luchando por ser fiel a la misma grandeza, pretendo adentrarme en su reflexión sobre el dolor y el poder de la fuerza como eje conceptual de tal reflexión, lo que sin duda atraviesa, en el sentido pleno de penetrar, la existencia misma de una mujer que se hizo esclava de la fuerza de su voluntad para ponerla al servicio de su pensamiento, de sus ideas de libertad.

En el presente texto abordo el tema del dolor y el sufrimiento desde la perspectiva de Weil; tomo el concepto de fuerza como eje central de análisis, y reflexiono acerca de tres temas fundamentales: 1. El lugar del sufrimiento

\footnotetext{
${ }^{1}$ Emile Chartier, llamado Alain (1868-1951), filósofo francés y profesor de Simone Weil en el instituto Henri IV, en donde la autora cursó el ciclo preparatorio para la universidad, llamado cagne. Alain influyó notablemente en su pensamiento.

${ }^{2}$ Según Weil, "Rhüle escapó a uno de los peligros de la biografía: escribir la vida de un santo, pero cayó en otro: contar la vida de un gran hombre, de forma tal que borra todo lo que pueda haber en él de superior a su propia alma de filisteo (...). Pero lo más odioso es que en general todas las mezquindades y todas las bajezas se nos cuentan de manera tal que aparecen como el precio de un genio" (Citado por Pétrement, 2001: 307-308). Estos aportes de la crítica que data de marzo de 1934 son recogidos por su amiga y biógrafa Simone Pétrement en su bella biografía de nuestra autora.
} 
en la vida y obra de la autora. 2. La fuerza como concepto central para entender las relaciones humanas, desde el análisis de su ensayo sobre $L a$ Ilíada y desde los diferentes elementos teóricos que la filósofa propone y, 3 . El impacto aniquilador de la fuerza, que obliga al ser humano a reconocer su condición frágil y finita.

\section{Dolor y sufrimiento en la vida y obra de Simone Weil}

A los CATORCE AÑos de EDAD, Simone WeIL sufre la que podría ser considerada la crisis fundamental de su vida intelectual, la que ella misma relata como "una de esas situaciones de desesperanza sin fondo de la adolescencia" (Weil, 1993: 39)3, que se desencadena ante el genio matemático de André, su hermano, frente al cual se siente torpe, limitada en su intelecto e incapaz de acceder a la verdad. Tras largos días de encierro, "de tinieblas interiores", resuelve su dilema con la revelación de que es posible llegar a la verdad si tan solo pone la voluntad al servicio del pensamiento. En efecto, "se puede acceder a ese reino de verdad reservado al genio, a condición de desear la verdad y hacer un continuo esfuerzo de atención para alcanzarla" (Weil, 1993: 39). Por ello este evento trasciende lo meramente anecdótico, lugar común en las biografías de la autora, para convertirse en una muestra palpable de su temple y temperamento, de los que dio señales desde niña y que la caracterizarían a lo largo de su vida, la cual realizándose en la práctica estuvo siempre puesta al servicio de la verdad y en la búsqueda de la libertad a través del pensamiento puro. Siendo coherente con lo anterior cayó en los límites que bordean la locura, único espacio en el que se puede concebir algo cercano a la explicación de la genialidad.

Pero, también, dicho episodio marca el inicio de un camino lleno de dolor y sufrimiento, no solamente de los que la vida le impuso de facto, sino los elegidos por ella, los auto-infligidos en consecuencia de sus convicciones, hasta el punto de que las experiencias narradas por sus biógrafos hablan de una desconexión con su cuerpo físico a no ser que fuera para torturarlo. Muestra de ello es que su conciencia precoz, e incluso su apropiación del dolor y del sufrimiento de los demás, de los desposeídos y desprotegidos, la llevaron a

\footnotetext{
${ }^{3}$ Esta anécdota es relatada por la propia Weil en una de las cartas enviadas desde Marsella al sacerdote dominico J. M. Perrin, titulada "Autobiografía”, fechada 15 de mayo de 1942 y publicada en su libro $A$ la espera de Dios.
} 
pensar el dolor, y, sobre todo, la encaminaron a la acción comprometida y profundamente vivencial de padecer las privaciones de los campesinos, los pescadores y los obreros, ya que al tratar de adquirir la forma de vida de cada uno de ellos, superaría el riesgo de que sus ideas flotaran en la abstracción y en la indiferencia afectiva propia de la falta de concernimiento.

Aunque no se trata aquí de establecer una relación entre Fichte y Simone Weil, es indudable que sus puntos de contacto van más allá de un simple recurso de escritura en el que se apela a esa interesante vinculación entre filosofía y alma humana. Ambos comparten en lo político el afán de libertad y la búsqueda de ideas para la superación del servilismo y, de igual manera, la afirmación del yo mediante el uso de la voluntad; por ello, nada se confirma más por contraste en la vida de la pensadora que las palabras del autor de la Doctrina de la ciencia: "Un carácter muelle por naturaleza o enmollecido y doblegado por la servidumbre de espíritu, la voluptuosidad refinada y la vanidad, no se elevará nunca hasta el idealismo" (Fichte, 1984: 46). En efecto, su temple de espíritu hace de Weil una mujer rotunda, profundamente inconforme, insurrecta ante la iniquidad y la injusticia y, por lo tanto, defensora de la verdad que habita en los seres desprovistos de la dignidad de la razón porque, para ella, solo en el espacio que deja la confrontación con la desnudez de nuestra alma, al desaparecer todo lo que creíamos poseer como propio, se manifiesta la auténtica verdad sobre la condición humana. La posibilidad de decir la última verdad la tienen exclusivamente los desposeídos, todos los otros mienten pero, ante su total orfandad, es fácil que ellos sean considerados locos y, por tanto, su expresión de verdad ni siquiera sea escuchada ${ }^{4}$.

En efecto, el dolor y el sufrimiento inherentes a la vida humana se ubican en el lugar de discusión cuando el hombre tiene la vivencia de la ausencia. El alejamiento o separación del otro que nos gratifica; el desposeimiento o carencia de las cosas que alivian muestras necesidades; la añoranza por la satisfacción de los deseos; el despojo de nuestros derechos y de las posesiones; el desalojo, el destierro, la agresión y la violencia que ponen en peligro la integridad del ser, son motivo de dolor y sufrimiento en los diferentes ámbitos de la existencia. La enfermedad, por ejemplo, se suele

\footnotetext{
${ }^{4}$ Esta tesis central del pensamiento de Weil la podemos encontrar en la carta enviada a sus padres, fechada 4 de agosto de 1943, 20 días antes de morir. Véase: Weil, 2007b: 197-198.
} 
definir técnicamente como la ausencia de bienestar, y el dolor, como la sensación poco placentera que nos trae a la conciencia no solo la ausencia de confort, sino la existencia de un órgano hasta entonces ausente: La cueva sombría del silencio, de la que a veces surge un apacible animal, como diría Trakl, esto es, el silencio de los órganos y de una psiquis sumidos en la armonía de los que surge el animal que representa la incomodidad de la corporalidad herida o injuriada.

Para Weil el dolor profundo es el gran enigma de la vida en el que encontramos la iluminación más intensa de la verdad. Sin embargo, el simple sufrimiento, inmanente al vivir, no es fuente de degradación para el ser, como lo es la verdadera desgracia, aquella que existe cuando el acontecimiento que se ha apoderado de una vida y la ha desarraigado la alcanza en todas sus áreas: física, social, moral y psicológica. La desgracia es el sufrimiento extremo, el despojo por excelencia, la carencia absoluta de atención y calor humano. Ligado a la desgracia, en Weil el término atención tiene un contenido profundo en su dimensión espiritual y en la intelectual, pues la desgracia se refiere al vaciamiento del ser para esperar la iluminación de la verdad; en su acepción extendida es el cuidado por el dolor del mundo que se traduce en amor al prójimo. Por ello cuando una persona sufre la indiferencia y el desamor del mundo está en auténtica desgracia.

En sus famosos cuadernos, que contienen apuntes de sus lecturas y reflexiones desde 1934 a 1942, Weil consigna una frase que a primera vista pareciera contradecir el valor que ella asigna al sufrimiento en la constitución de lo humano. "Creo en el valor del sufrimiento en la medida que hacemos todo (cuánto hay de honesto) para evitarlo" (Weil, 2001: 77), lo que en apariencia contradiría también su propia renuncia a los placeres, o por lo menos, su resistencia a evitar el dolor. Entre esos retazos de ideas y fragmentos discursivos, más adelante expresa la autora:

Todo lo que es menor que el universo queda sometido al sufrimiento (al ser parcial está, por tanto, expuesto a las fuerzas externas) (...).

Aunque yo muera el universo continúa. Esto no me consuela si yo soy distinta del universo. Pero si este está en mi alma como un cuerpo más, mi mente deja de tener para mí más importancia que la que un desconocido cualquiera. Y lo mismo mis sufrimientos (Weil, 2011: 151).

Lo cual implica que el sufrimiento propio, físico o de cualquier índole, puede ser soportado, no solo porque logra fundir al sujeto con el universo, sino 
porque ante el propio dolor, puede este hacer el ejercicio de la atención, del vaciamiento de su ser, para lograr la iluminación de la verdad. Sin embargo, ante la desgracia que sufren los desposeídos, nos encontramos en otro plano del sufrimiento, aquél en el que surge la indignación y la rebelión. Se trata entonces del dolor por el sufrimiento del mundo, el que Weil reiteraba sentir y no tolerar, sin que ello significase la renuncia al pensamiento y a la acción; por el contrario, debemos "evitar al máximo las situaciones en las que las reacciones brutas de la sensibilidad puedan entrar en contradicción con los sentimientos superiores de la voluntad" (Weil, 2001: 81).

Para entender el sufrimiento es necesario desarrollar la intuición, pues ni el pensamiento ni el discurso son suficientes para ello porque no brindan la posibilidad de progresar en argumentación ni en revelación (Cfr. Weil, 2001: 695). Con esto caemos de nuevo en el plano individual: ante el fracaso de avanzar en el pensamiento sobre el sufrimiento, se nos obliga el desarrollo de la facultad de la intuición, que nos permitirá la conexión con lo universal y la trascendencia. A través de estas palabras en las que pareciera existir una contradicción en lo relacionado con el ejercicio del pensar, habla la idealista, la mística, una de las facetas de este ser de temperamento tan complejo, que descubrió a Cristo entre los excluidos como uno más de ellos, sin voz, y que en su desnudez, sin embargo, tiene la verdad de la condición humana y grita su profunda desgracia. Así, el pensamiento solo es verdadero cuando se impregna de la sabiduría suprema.

Sin embargo, por esas eterna e incondicionadas obligaciones hacia el ser humano como tal, las cuales Weil enumera en Echar raices, cuyo cuidado a lo largo de su vida fue más que una formalidad ética, debemos privilegiar su faceta de inconforme, aspecto que tampoco se aleja de su conversión a Cristo, más no a la iglesia a la que, precisamente, siendo coherente con lo que siempre declaró y actuó sobre su total repulsión hacia todo tipo de alejamiento, dominio y coerción, rechazó por su tendencia a la exclusión de los no creyentes. Así, durante toda su vida Weil privilegió el ejercicio de la razón y de las ideas como parte de esa obligación frente a la sacralidad del ser humano.

Simone Weil padeció, en su cuerpo y su alma, el dolor físico, aprendió a manejarlo y ponerlo al servicio de sus aspiraciones de alcanzar la verdad. Así, a través de los dolores de cabeza que sufrió desde los 21 años de edad y de su problema con la alimentación, que le permitieron solidaridad absoluta 
con los que sufrían hambre, ella misma se cometió a la frugalidad ${ }^{5}$. Sufrió la explotación de los obreros, al trabajar con ellos en una de las fábricas emblemáticas del mundo capitalista: la Renault; se fue al campo a convivir con campesinos y tuvo experiencias con pescadores y marinos, todo ello, para encontrar respuestas acerca del dolor y el sufrimiento. Pero fue incluso más lejos. Con una vida que se desplegó en el período llamado de entreguerras, tuvo la oportunidad de estar en contacto con el dolor, con la soledad y con el abandono provocado por la guerra, primero, a través de su padre, médico que

\footnotetext{
${ }^{5}$ Es importante resaltar aquí el lugar que ocupa la relación que Weil tuvo con la alimentación. Su biógrafa Pétrement narra el inicio temprano de este problema, cuando a los 11 meses de nacida sufre apendicitis, como meses antes, su madre. A partir de allí la niña quedó muy afectada en su salud y solo recibía biberón, por lo cual se retrasó en su desarrollo. A los 3 años de edad se repitió el episodio de apendicitis que obligó a operarla, presentando complicaciones postoperatorias que pusieron en serio riesgo su vida. A la par con estas dificultades físicas, la pequeña Simone daba muestras de facultades excepcionales en su desarrollo intelectual y en una sensibilidad especial frente al sufrimiento ajeno y a la sencillez de una vida sin lujos (Pétrement, 2001: 21-22). Sin embargo, la obra de Weil está indisolublemente ligada a su carácter y natural condición humana, de tal manera que estos aspectos han sido objeto de diversas interpretaciones en los innumerables comentaristas de su producción intelectual. Por ejemplo, los teólogos cristianos la reclaman para su causa, como una mística que hizo de su vida una obra de amor a Dios. Peter Sloterdijk destaca su lugar en el mundo de la ascesis, como una artista del hambre, evocando el relato de Franz Kafka de 1922 (esta evocación de la narración kafkiana aplicado a Weil lo hace ya en 1994 Carlos Ortega, en su introducción a la edición en español del texto de la autora: La Gravedad y la Gracia). Mientras Ortega la asimila al artista del hambre en la medida en que no es escuchada para evitar responder a la pregunta acerca de si dice o no la verdad, una verdad que no se siente merecedora de poseer, Sloterdijk, en su estilo procaz, atribuye la resistencia de Weil a una determinación thymótica: "Combatiente de la resistencia y existencialista de la pertinacia, quiso pasar hambre al lado de la clase obrera para ennoblecer así su falta de apetito y humillar su misma nobleza" (Sloterdijk, 2011: 101). Si esta afirmación se toma como una explicación psicológica ofendería de manera sustancial a Weil por su rechazo a este tipo de atribuciones causales en la obra de un gran personaje. De la misma manera, rebajaría la condición trascendente de las convicciones de la autora que van más allá de una pose intelectual o un mecanismo psíquico de defensa. Como lo diría Susan Sontag (1963), en su exaltación al respeto que inspira la pensadora: "Nadie que ame la vida quisiera imitar su dedicación al martirio, y no lo desearía para sus hijos ni para ningún otro al que amara. Sin embargo, en la medida en que amamos lo serio, tanto como la vida, nos inquieta, nos alimenta. En el respeto que sentimos por esas vidas, reconocemos la presencia del misterio en el mundo, y el misterio es precisamente lo que desmiente una segura posesión de la verdad, de una verdad objetiva. En este sentido, toda verdad es superficial y algunas (pero no todas) distorsiones de la verdad, algunas (...) demencias, alguna (...) reacción enfermiza, algunas (...) negaciones de la vida, permiten la verdad, producen cordura, crean salud y enaltecen la vida" (Sontag, 2008: 73).
} 
sirvió en el frente de batalla durante la Primera Guerra Mundial y, al tiempo, en la experiencia precoz de ser madrina a sus siete años de un soldado que luchaba en el ejército francés. Después, en la Guerra Civil Española, con su fallida participación como combatiente y, finalmente, durante la Segunda Guerra Mundial, de la que no vio el desenlace por su muerte prematura. Fue en esta última experiencia en la que tras su refugio en Marsella publicó uno de sus escritos más lúcidos y hermosos, del que nos ocuparemos para trabajar sus aportes en el tema del dolor y el sufrimiento: La Ilíada o el poema de la fuerza.

\section{La Ilíada o el Poema de la Fuerza}

Simone Weil Resume en los Siguientes términos la gran enseñanza de la guerra: "No creer nada al abrigo de la suerte, no admirar nunca la fuerza, no odiar a los enemigos y no despreciar a los desdichados" (Weil, 1942: 310). Los 40 días de la guerra de Troya, objeto de La Ilíada, muestran la crudeza de la violencia, sin ambages, pero también sin exaltaciones de victoria ni gritos de presunción o soberbia; no se trata de una apología de la guerra, por el contrario, es un canto a la desnudez del alma, un alma expuesta a los rigores de la fuerza. Fuerza es el término que Weil utiliza para lo que podríamos llamar violencia o impulso hacia la utilización de actos violentos. Fuerza es uno de los términos que en el diccionario de la lengua española tienen más acepciones, lo mismo que en francés 6 . Sin embargo, en el discurso de Weil la fuerza está muy ligada al impulso y, por tanto, a la materia. De cualquier modo, su sentido y significación se irá dilucidando a lo largo de esta presentación.

\footnotetext{
${ }^{6}$ El Diccionario de la Real Academia Española da cuenta de 16 acepciones, entre ellas: vigor, robustez y capacidad para mover algo; aplicación del poder físico y moral; capacidad para soportar un peso o resistir un empuje; virtud y eficacia natural de las cosas; acto de obligar a alguien; estado más vigoroso de algo; violencia que se hace a alguien; etc. Por su parte, el Larousse Français enumera 11 acepciones, v. gr. énergie (energía), moyens violents (recursos violentos), capacité de résister aux épreuves (resistir una prueba), savoir (saber), habilité (habilidad), poids (peso), assurance (seguridad), vigueur (vigor), pouvoir (poder), puissance (capacidad), etc. Así también, el Centre National de Ressources Textuelles et Lexicales - CNRTL registra en francés innumerables usos de force. Divide esos usos en dos categorías semánticas: 1 . Como una propiedad de las personas y 2. Como una propiedad de las cosas; cada una de ellas dividida en varias sub-categorías con innumerables usos.
} 
Sobre La Ilíada se han escrito infinidad de ensayos, libros y tratados, acerca de los más insospechados temas y tópicos que rodean el poema más antiguo de la literatura occidental, pero en la Francia amenazada por la embestida nacional-socialista, obligada a la participación activa en la Segunda Guerra Mundial, la autora, tal como las circunstancias imponían a los pensadores de la época, reflexiona en medio de su afán guerrerista aunque suene paradójico, ese era el temple weilniano: marcado por los contrastes y la paradoja- acerca de la violencia y su influjo sobre el hombre. Tal vez porque aceptaba la inevitabilidad de la guerra y pensaba que tendría que existir una salida para que esta fuera menos aniquilante, a lo cual quería contribuir de manera directa; ejemplo de ello es su propuesta sobre mujeres enfermeras al frente de batalla ${ }^{7}$, como también lo es su necesidad de participar activamente en la guerra.

De cualquier modo, la historia de la humanidad y el fracaso histórico de la humanización de la guerra ha demostrado la imposibilidad del hombre para sustraerse, constantemente desde la Revolución francesa, de ella. Por tal motivo, qué bueno tener la fuerza del pensamiento y las ideas contra el poder de la violencia; así, no obstante las limitaciones físicas que imponían su constitución y su salud siempre precaria, Weil agregaba un espíritu combativo que la impelía a estar en el frente de batalla. Ello simplemente actualiza la convicción de la propia autora de que nadie se substrae de la guerra, ni siquiera la mística Simone, porque la subordinación a ella "es igual para todos los hombres, aunque el alma la lleva diferentemente, según el grado de virtud" (Weil, 1942: 307). Y fue su grado de virtud elevado a consideraciones de justicia y libertad, acorde con su afán de escribir tan bellamente sobre la guerra en una evocación a la integridad y a la virtud griegas, lo que la llevó a concebir planes de estrategias militares tendientes a la humanización, proyectos considerados inviables y poco realistas.

La disertación sobre la condición humana y social que Simone Weil hace a lo largo de su corta vida intelectual se desarrolla a partir de una crítica hacia los derechos humanos, concebidos en términos abstractos, y a "la persona humana", surgida de la noción de derecho establecida con la

\footnotetext{
${ }^{7}$ Propuesta consignada en un texto adjunto a una carta enviada a Maurice Schumann, fechada desde New York, 30 de julio de 1942, publicada en Escritos de Londres y últimas cartas.
} 
Revolución francesa. De este modo, dado que no es el reconocimiento de la humanidad del otro lo que impide hacerle daño, es el propio hombre en cuanto ser sagrado, en cuanto es expresión del Bien, el que exige hacer el bien y que, cuando dicha dignidad es vulnerada, grita contra el mal. Este grito no es algo personal, sino que brota siempre a causa de la sensación de un contacto con la injusticia a través del dolor. Y eso impersonal es lo sagrado, solo eso. La distancia que Weil toma de lo personal ante el compromiso del contacto con el otro se deja ver en su construcción sobre lo humano del hombre, pues se trata de la negación del yo que en ello se afirma, puesto que dicha aversión por el contacto solo se reduce a lo físico y hace parte de su misticismo más allá de lo religioso. Ella siempre pretendió trascender este plano material para fundirse en lo universal, porque su obligación fue únicamente con la sacralidad del hombre. De ahí se entiende su compromiso con los seres despojados de su dignidad, con el que pretende elevar el dolor y el sufrimiento que impone la condición material hacia formas elevadas del ser. Por ello, el hambre física debe ser satisfecha para atender a la lucha por compensar las necesidades del alma humana; el despojo y el desarraigo deben ser suplidos con una total adhesión a los deberes en vez de un reclamo por los derechos. El orden, la libertad, la obediencia, la responsabilidad, la igualdad, la jerarquía, el honor, el castigo, la libertad de opinión, la seguridad, el riesgo, la propiedad privada y colectiva y, por supuesto, la verdad, son las necesidades que Weil enumera y define como inherentes al alma, de la misma manera que la necesidad de alimento, de sueño y de calor lo son a la vida del cuerpo (Cfr. Weil, 1996: 27 ss).

Pero la necesidad de enraizamiento o arraigo es, de alguna manera, la que subyace a las otras necesidades, pues dispone de las condiciones de posibilidad de las restantes. Cuando hay desarraigo se instaura una enfermedad casi letal para los sometidos. Pensemos en este caso en las comunidades, familias o individuos que son desterrados o desplazados de sus entornos naturales, de sus propiedades, por cuenta de intereses económicos o políticos, tales como los pogromos que se han dado en Europa o los desplazamientos forzosos en Colombia, de cuyos efectos no son suficientes los estudios por parte de las diferentes áreas del conocimiento para alcanzar a dimensionar el impacto del desarraigo y la discriminación sobre estos seres. Weil llama la atención del poder del dinero y la dominación económica que causa el desarraigo, por ejemplo, en los obreros que, aunque no son movilizados geográficamente, lo son moralmente, o el de los campesinos que, además, son desarraigados brutalmente de las cosas del espíritu. Pero, de igual manera, nos advierte 
la pensadora sobre otro factor de desarraigo distinto al dinero, que es la instrucción educativa, la cual separa a letrados de iletrados, a "cultos" de los que siguen la tradición de las masas que, a su vez, causa otra fractura entre lo que se enseña teóricamente y la realidad que lo circunda. Sin embargo, pese a que todos los tiempos han creado sus propias modalidades de desarraigo, la modernidad configuró unas condiciones que han hundido en la desdicha del cuerpo y del alma a los seres humanos; por eso, según Weil, Francia se hundió bajo la lamentable condición de desarraigo en que estaba sumida en los tiempos de entre guerras, de ahí que ella diera algunas indicaciones para su reconstrucción después de la primera ${ }^{8}$.

No obstante la importancia de la necesidad como noción fundamental para comprender al hombre y sus circunstancias sociales en la obra de Weil, la de fuerza es la categoría que constituye la clave de lectura de los fenómenos sociales (Weil, 2007a: 112). Desde las pasiones, que obstaculizan no solo el desarrollo sino también el estudio de los mecanismos sociales, se perpetúan relaciones de sumisión y dominio. La minoría domina a una inmensa mayoría, lo que excluye el hecho de que el número sea una fuerza. Hay otros factores que determinan la fuerza, el principal es que la minoría es un conjunto cohesionado que actúa metódicamente, mientras que las masas solo son suma de individuos yuxtapuestos que, ante condiciones excepcionales, se unen eventualmente, comparten intereses, emociones e ideas emancipadoras pero que, por la ausencia de método, dicha masa rápidamente se disuelve en el individuo, esto es, se difuminan las emociones y, ante la represión de los amos, vuelve al sentimiento de impotencia.

\footnotetext{
${ }^{8}$ En la obra y apuntes de Weil no existen indicios de que haya leído a Heidegger ni se encuentran alusiones al poeta Hölderlin; sin embargo, las consideraciones de la autora sobre los desposeídos resuenan con las palabras atribuidas a Hölderlin, que Heidegger tomó como base de la conferencia que leyó el 27 de junio de 1945, poco tiempo después del fin de la Segunda Guerra Mundial: "Entre nosotros, todo se concentra sobre lo espiritual, nos hemos vuelto pobres para llegar a ser ricos". En ese ambiente de hundimiento en que se encontraba la Alemana nazi, curiosamente, el pensador acusado de connivencia con el régimen que impuso Hitler, hace aquí una reflexión de este verso que exalta el valor de la espiritualidad en el hombre. Dice Heidegger: "Por el hecho mismo de que la pobreza no nos hace carecer de nada, tenemos de entrada todo, nos mantenemos en la sobreabundancia de Ser, que desborda por anticipado todo lo necesitante de lo necesario (...). La pobreza es la alegría ensombrecida de no ser nunca bastante pobre. En esta calma inquietud reposa la serenidad, habituada a poner fin a todo cuanto atañe a la necesidad (apremiante)" (Heidegger, 2008: 115).
} 
En cada extremo, y de acuerdo con el lugar que ocupe, cada actor se siente superior o inferior, y en esa interacción se refuerza la situación de dominio-sumisión. Los poderosos hacen creer a los sometidos que no tienen ningún valor y estos caen en tal error; por esto, todo aquello que contribuya a brindar a los desposeídos un sentimiento de valor es subversivo. El cristianismo o el marxismo, por ejemplo, fueron subversivos al brindar, el primero, un valor interno espiritual y, el segundo, un valor material en su fuerza de trabajo. Esto tiene, sin duda, su costo, pues no hay ser que quiera poner la pureza de su espíritu al servicio de la acción política que no sufra las consecuencias de la fuerza bruta. Todo ello deja al descubierto que la fuerza social no es ajena a la mentira y que las clases sociales no se mantienen por virtud, sino por la fuerza que implementa la una sobre las otras, que se resignan por un sentimiento de humillación que somete en ellos las virtudes civiles. Cuando la muerte impera, estalla ante nuestros ojos el milagro de la obediencia (Weil, 2007a: 115).

Ante ese irreductible compromiso social y político, Simone Weil planteó ideas y propuestas, siempre en términos profundamente espirituales, no religiosos. Ideas, para contribuir a la creación de un orden diferente, y planteamientos que crearían polémica e incredulidad en los círculos en que se leyeron sus escritos, incluso entre sus más cercanos compañeros que consideraban dichas ideas poco viables. Buscar y "hallar un método que permita dotar de inspiración a todo un pueblo" (Weil, 1996: 149), era su propuesta. Inspiración que incluye una labor de humanización, de reconocer lo sagrado del hombre y de suscitar móviles a través de la educación, es decir:

[de] transmitir la necesidad indispensable de un interés apasionado por los seres humanos, cualesquiera que sean, y por su alma: la capacidad de ponerse en el lugar del otro y de prestar atención a los signos de los pensamientos no expresados; cierto sentido intuitivo de la historia en curso de realización, y la facultad de expresar por escrito matices delicados y relaciones complejas (Weil, 1996: 158).

Como vemos, esta es una propuesta de ejecución efectiva que debe cumplir la educación para los pueblos, evitando que el pensar sea un simple ejercicio de privilegio. De igual manera, a los campesinos les convendría mucho lo que sería una medida "en virtud de la cual la tierra fuese considerada un medio de trabajo y no riqueza para ser repartida en herencia" (Weil, 1996: 78), lo mismo que los obreros que lograrían salir de la desgracia 
y el desarraigo al instaurar una civilización basada en la espiritualidad del trabajo, lo que "sería el grado más elevado de arraigo del hombre en el universo" (Weil, 1996: 88). El trabajo debe contribuir a la superación del sentimiento de alienación que inevitablemente sufren los obreros; para ello, no solo sería necesario la liberación de la máquina y de la opresión de los propietarios, sino también el poner punto final a la división del trabajo manual y del trabajo intelectual, y sacar al obrero de la alienación a la que lo somete la imposibilidad de pensar. Estos planteamientos constituyen elementos de superación de la barbarie en que viven los oprimidos.

El arraigo o, su contrapartida, el desarraigo constituyen, junto con el concepto de decreación, un par de elementos teóricos que sustentan el pensamiento weilniano en sus dos vertientes: la política y el misticismo. El hombre debe liberarse de la opresión y de la alienación del pensamiento, mientras que los estados y gobernantes están en la obligación de crear condiciones que lo posibiliten llevándolo a cabo por una sencilla razón: la sacralidad del ser humano. Lo sagrado en el hombre radica en su aspiración al bien, única fuente de lo sagrado. Para respetar ese carácter, la persona debe elevarse a lo impersonal, con lo cual garantiza el respeto por lo sagrado, sin caer, empero, en el peligro de contaminarlo con cualidades o atributos personales que condicionarían este respeto. Basta el reconocimiento del otro como aquel en cuyo ser habita el bien y, en consecuencia, no se pueda mancillar. Desde este punto de vista, el reconocimiento de lo sagrado sería condición de posibilidad para la convivencia y la justicia social. Así pues, para que esta dignidad de lo sagrado se conserve es necesario que la existencia no sea considerada un bien en sí mismo, como sucede con los esclavos, que no pueden aspirar ni al reconocimiento de lo sagrado de su persona ni a ningún otro bien que se añada a su existencia, pues solo luchan por ella como un mero bien en sí, desnuda y vacía, desprovista de deseos elevados. La vida y las actividades de los esclavos giran en torno a la satisfacción de necesidades básicas, pero hay que tener presente que la existencia ya se posee.

A lo que se tiene que aspirar es a llenar la existencia de bienes, es decir, se necesita que el alma se dirija a lo único hacia lo que debe tender: a la belleza, condición natural del alma que se constituye en pan espiritual para los desposeídos. El pueblo necesita que la substancia cotidiana de la vida sea ella misma poesía, cuya única fuente puede ser Dios. Por eso, los obreros, campesinos y demás seres excluidos deben transformar sus medios e instrumentos de trabajo en espejos de luz que los lleve a la transfiguración 
del trabajo y de cada tarea en su singularidad. Para el obrero, el trabajo físico debe ser su centro espiritual. En esta actitud se puede explayar el acto de decreación, término y concepto que utiliza Weil para plantear la creación del mundo como un desbordamiento del amor de Dios y no como una manifestación de su poder, porque en la medida en que crea el mundo, junto con nuestra existencia, nos da la posibilidad de acceder al consentimiento de no ser, de no existir 9 . Cuando el hombre asume al otro en su sacralidad no está haciendo otra cosa que desbordando en él su empatía y amor en el reconocimiento de su propio valor y derechos, iguales a los propios. Esto sucede también cuando se relaciona de la misma forma con su trabajo. El acto decreativo debe no solo sustentar una conducta ética en relación con el otro, debe también extenderse a todas las actividades de la vida.

Por otro lado, "cuando debido a la acción u omisión de otros hombres, la vida de un hombre sufre daño, destrucción, mutilación o privación del alma o del cuerpo, no solo la sensibilidad sufre el golpe sino también la aspiración al bien. Entonces ha habido sacrilegio hacia lo que el hombre encierra de sagrado" (Weil, 2007b: 65). Para Weil, este sacrilegio es posible cuando el hombre es sometido a condiciones de desgracia, aquella que sufre ante la absoluta falta de atención, ante el desarraigo, la esclavitud y, en especial, ante el silencio o la imposibilidad de expresar su sufrimiento. En la desgracia se encuentra también el que somete al otro porque está traicionando su propia sacralidad; el indiferente ante la desgracia del otro porque desconoce el poder sanador en doble vía de la compasión, en tanto esta lleva implícito el reconocimiento de la sacralidad del que sufre y cura al desgraciado del mayor sufrimiento que es el de sentirse un sujeto anónimo, invisible, inexistente para los demás. Sin embargo, que los poderosos sientan compasión por los sometidos sería un auténtico milagro. En este sentido, la desgracia es el epílogo de la fuerza.

9 Simone Weil define esquemáticamente el concepto decreación (algunos escriben "descreación") como "hacer que lo creado pase a lo increado", y lo opone al término destrucción, al que define como "hacer que lo creado pase a la nada. Sucedáneo culposo de la decreación" (Weil, 1994: 81); en este sentido, en la medida en que la creación es un acto de amor perpetuo, las necesidades y los sufrimientos son obra divina, pues Dios se retira de nosotros para que podamos amarle. De ahí que podemos afirmar que la decreación es una manifestación del amor de Dios y no de su poder. Dios renuncia a ser todo, por ello nosotros debemos renunciar a ser algo, como una imitación de la renuncia divina. 
Hasta ahora hemos explorado los conceptos fundamentales de la obra de Simone Weil y hemos resaltado los elementos que hacen de ella un ser humano excepcional, al mismo tiempo que una pensadora de su época, en la medida en que su vida transcurre entre guerras. Por esta razón, podemos decir que su existencia estuvo marcada por la fuerza desde diferentes ángulos de su significación: la de su tiempo, aquella cuyo influjo experimentó de forma cruda y la de su propia naturaleza. Es decir, el talante natural por luchar desde muy niña contra los sufrimientos físicos, su fuerza de voluntad llevada a extremos en aras de un pensamiento puro y su rebeldía ante cualquier tipo de opresión y sujeción, la llevaron a asumir el acto supremo de total obediencia: su consentimiento para no existir más. ¿Cómo no comprender la profundidad y la belleza de sus reflexiones en torno al dolor y al sufrimiento? ¿Cómo no entender su fascinación por la integridad de los griegos de la época clásica ante el sufrimiento y la muerte? Estos elementos de reflexión son el objeto del siguiente apartado.

\section{La fuerza o la aniquilación del ser humano}

Que Aquiles SEA El hÉROE DE LA ILÍADA o que más bien sea Héctor quien representa mejor esta dignidad no es asunto problemático para Simone Weil, porque realmente el verdadero héroe de este poema épico, para la pensadora, es la fuerza. La fuerza que somete a los hombres, aquella ante la que se repliega cualquier voluntad, incluso la del héroe. La fuerza está en el centro de toda historia humana y convierte en cosa a cualquiera que le esté sometido, de manera literal y extrema, porque lo convierte en cadáver. Hace parte de la condición humana y es inevitable que el alma caiga bajo su dominio; aunque no toda la fuerza mata, la fuerza que constituyen los hombres en la guerra es fuerza destructiva, es una forma grosera de la fuerza, impulso ciego que aniquila. Sin embargo, no nos llamemos a engaño, la fuerza en todo caso destruye, solo que hay diferentes aristas del problema, pues junto al cadáver físico también puede existir el ser convertido en cosa, un ser petrificado o un alma habitando una piedra. Pero el alma no puede habitar una cosa; ella, al ser obligada a habitar una cosa ya nada la salva del desgarro de la violencia, solo habita al ser vivo. Y esa cosa puede corresponder al ser sometido por la violencia, pero también al que somete.

Si aceptamos entonces que la noción de fuerza es la clave para leer los fenómenos sociales, no resulta extraño que la guerra, lugar de despliegue abierto y espontáneo de la fuerza, sea un acontecimiento de reflexión para 
la autora. Además de que su vida estuvo enmarcada entre las dos guerras mundiales, ella nos recuerda que no hay época en la historia de la humanidad libre de barbarie, pues esta depende de la distribución de la fuerza, así que se es siempre bárbara ${ }^{10}$ con los débiles (Weil, 2007a: 87).

El concepto de fuerza tiene dos fuentes de inspiración para Simone Weil. En primer lugar, la noción dinámica de la fuerza, enunciada por Galileo en la física, en el sentido de que un cuerpo sobre el que no actúa ninguna fuerza permanece en estado inalterado, concepto que luego sería desarrollado de mejor manera por Newton. Pero la filósofa nos deja también en sus propios escritos más pistas sobre esas fuentes de inspiración; por ejemplo, en sus Cuadernos consigna la frase de Tucídides en el tomo V de La guerra del Peloponeso, en el famoso diálogo entre melios y atenienses: "Cualquier ser ejerce siempre, por un requisito natural, todo el poder del que dispone" (Weil, 200: 344) ${ }^{11}$. Esta idea la reitera Weil a lo largo de sus escritos para sustentar su convicción de que no se pueden tener pensamientos claros sobre las relaciones humanas en tanto no se haya puesto en el centro de la reflexión la noción de fuerza. Empero, hay que delimitar este concepto, pues la pensadora señala que desde hace dos o tres siglos se cree que la fuerza es el dueño único de todos los fenómenos de la naturaleza, razón por la que los hombres deben esforzarse por fundamentar sus relaciones mutuas en la justicia reconocida por medio de la razón, lo cual resulta absurdo, pues no es posible sustraerse de la fuerza, cuando el hombre "está hecho de carne y sangre y su pensamiento vaga al azar de sus impresiones sensibles" (Weil, 1996: 87).

\footnotetext{
${ }^{10}$ Este término es equivocado e injusto, si se utiliza como sinónimo de violencia, porque los bárbaros, paradójicamente, no instrumentaron episodios de destrucción gratuita. Los griegos llamaban bárbaros a aquellos pueblos extranjeros que no hablaban su idioma, después el término se impuso para denominar a los pueblos no civilizados y sin educación. Pero se ha instituido finalmente como sinónimo de violencia, hasta el punto de que Walter Benjamin asoció el progreso con la barbarie: "No existe documento de cultura que no sea a la vez documento de barbarie" (Benjamin, 2010: 29, frg. VII) con lo que apoya el uso que se ha impuesto para adjetivar los actos crueles e inhumanos para infligir sufrimiento de manera deliberada y causar muerte en forma premeditada. En términos weilnianos, barbarie es el uso indiscriminado e irracional de la fuerza. La misma idea de Benjamin la enunció Weil en forma más poética: "La historia es un tejido de bajezas y crueldades donde de tarde en tarde brillan unas gotas de pureza" (Weil, 1996: 181).

${ }^{11} \mathrm{Si}$ bien esta anotación se halla a pie de página en Cuadernos, no deja de ser recogida de manera reiterada en la mayoría de las obras de Weil.
} 
Pero aquí hay una trampa o mentira que ha circulado a lo largo de las etapas de la historia bajo diferentes modalidades pues, por un lado, se ha aceptado que puede existir un principio paralelo a la fuerza, distinto a ella $\mathrm{y}$, por tanto, organizador de las relaciones humanas; con lo cual se entra en contradicción con la ciencia moderna. Pero, por el otro, se puede creer también en la fuerza como dueña soberana de esa interacción entre los hombres, lo cual estaría en contradicción con el humanismo; de tal manera que se ha tratado de resolver la contradicción entre ciencia y humanismo, pero sin hacerla evidente. El utilitarismo la resuelve planteando que la fuerza se convierte automáticamente en productora de justicia. El liberalismo del siglo XIX, por su parte, cree en ello, pero implementa un condicionamiento: la fuerza debe tener la forma del dinero para producir el milagro de la justicia. Mientras tanto, en el marxismo, el mecanismo cambia y la fuerza toma el nombre de historia en forma de lucha de clases y la justicia llegará en el futuro después de una revolución. Obviamente, Hitler no puede excluirse de tal elucubración con fines de dominación, sin la lucidez intelectual para elegir algo diferente a un modelo de máquina, encontró el argumento en las profundidades de sus pasiones, que lo dirigían como marioneta a cumplir su misión de odio y destrucción. Este argumento es la raza elegida, que al erigirse como soberana llevaría a establecer la justicia adecuada a la esclavitud. Cada una de estas tendencias confirma la sentencia de que la fuerza social no puede ser ajena a la mentira, cada mecanismo esgrimido no es más que una sustentación o fundamento para la esclavitud, cosa que hicieron tanto Aristóteles como Santo Tomás, que solo siguió al primero en su concepto de justicia, pero ante el que Weil no transige en sus convicciones: "un hombre que se toma el trabajo de elaborar una apología de la esclavitud no ama la justicia" (Weil, 1996: 189).

La fuerza no puede crear automáticamente la justicia porque no es una máquina, aunque sí es un mecanismo ciego del que azarosamente salen efectos justos e injustos, casi siempre injustos por el juego de las probabilidades. En esta eventualidad cualquier creencia, la fe en una raza, nación, clase social, partido, etc., resulta peligrosa. Y aunque buscamos las causas de la barbarie afuera, Weil propone, más bien, pensarla como una característica permanente y universal de la naturaleza humana, que se desarrolla en mayor o menor medida según las circunstancias, sean más o menos favorables (Weil, 2007a: 272). No podríamos traducir esto como una resignada posición de mantenimiento de lo establecido, nada más alejado del carácter y temple de la autora. Por el contrario, hay en su proceso reflexivo 
una reivindicación de lo verdadero y auténtico del ser humano: la aspiración a la verdad, la que traiciona la ciencia moderna con su afán pragmático y materialista; aunque también lo hace la religión cuando sus juicios y moral están en contradicción no solo con la ciencia, sino también con los principios del cristianismo, en el caso de los cristianos. Y el espíritu de verdad solo es posible lograrlo, según Weil, en la entrega incondicional y libre de prejuicios al dogma cristiano, lo cual incluye deshacerse de la religión y liberarse de la aspiración de creer para vivir, pues la vida no es la verdad, solo la muerte es verdadera, en tanto con ella obtenemos otra vida que en cuanto tal no es vida sino verdad.

Todo lo que apunte a la consecución del bien, al espíritu de la verdad, se orienta a la justicia, entendida como providencia divina, que no es sino el orden del mundo mismo. Si la religión y la ciencia asimilan la idea de que el universo en que nos hallamos no es más que obediencia perfecta y si aceptan el hecho de que el hombre debe vaciar su alma para dejar entrar en ellos la sabiduría eterna, podrán tener la llave para liberar al alma de lo que la mantiene sometida a la fuerza, esto es, del imperio de las necesidades, pues habrían comprendido, como los griegos, que la necesidad debe ser realmente obediencia a Dios. Se trataría de la ciencia en vínculo con la fe mediante "esa sola cosa, que en relación a Dios es la eterna sabiduría, en relación al universo es la obediencia perfecta, en relación a nuestro amor es belleza, en relación a nuestra inteligencia es equilibrio de relaciones necesarias, y en relación a nuestra carne es fuerza bruta" (Weil, 1996: 226). Si esto se lograra, no se seguiría ofreciendo fuerza bruta al pensamiento de los hombres, que es lo que brindan la ciencia, la historia, la política y la religión.

Aceptar y vivir esta verdad es para Weil asumir la aceptación de la muerte como vía de acceso a dicha verdad, pero también es la aceptación del trabajo físico como algo sagrado, esto es, volver a su significación original que lo despoja de su carácter de castigo y lo convierte en una actividad religiosa. Es decir, la pensadora mística sostiene que la muerte y el trabajo impuestos por Dios al hombre por su pecado no son más que vías de purificación a través del dolor para volver a la verdad y al bien supremos. Hacer del trabajo el centro espiritual de una sociedad implica una reivindicación de los fines que la deben regir en su organización y, con ello, obtener el rasero con el que deben realizarse las relaciones humanas. En este sentido, una civilización basada en la espiritualidad del trabajo se erigiría libre de esclavitud, sería una condición opuesta al estado en que nos encontramos, 
consistente en un desarraigo casi total. Esta es, por naturaleza, la aspiración que corresponde a nuestro sufrimiento, pues “después del consentimiento de la muerte, el consentimiento a la ley que hace indispensable el trabajo para la conservación de la vida es el acto de obediencia más perfecto que puede realizar el hombre" (Weil, 1996: 231).

El hombre debe aspirar al bien y, en sintonía con el orden impersonal y divino del universo, solo puede tener como imagen el imperio de la justicia, la verdad y la belleza, opuestas a lo que aplasta a las almas bajo la injusticia, la mentira y la fealdad. Sin embargo, el orden de nuestro mundo se orienta por la fuerza, por el poder, real o no, en todas sus formas, que hace que cada grupo humano se sienta legitimado como dueño y amo del universo. Esto lleva a la guerra, haciendo a un lado la verdad de que tal lucha por obtener el dominio absoluto pasa por el propio cuerpo, es decir, pasa por la esclavitud ante la fuerza que destruye y cosifica. El orden social no puede ser más que un equilibrio de fuerzas, solo el equilibrio destruiría y anularía la fuerza; pero el desequilibrio siempre ha de existir, pues no vivimos en el mejor de los mundos posibles, pero sí en uno que nos brinda por igual dosis de bien y mal en gradaciones diferentes, uno en el que las fuerzas se contraponen, en la medida en que se vive en el reino de la necesidad. Si existe equilibrio, este solo existe entre fuerzas desiguales y en condiciones de integridad y de dignidad excepcionales.

He aquí la excepcionalidad del pueblo griego exaltada en poemas y obras inmortales que, no obstante su dramático contenido, no dejan tristeza sino, por el contrario, transmiten una impresión de serenidad. Los dramas de Sófocles, por ejemplo, son modelos de lucha y de dignidad, como también demostraciones de la inexorabilidad de las consecuencias de las acciones y decisiones humanas, que nos exaltan por contraste el valor de la grandeza y la mesura. Esto restituye en el espectador tanto la pureza de la víctima como la justicia, la verdad y la belleza del mundo. De aquí que Simone Weil mostrara predilección por obras como Antígona o Electra, personaje este de quien decía le brindaba consuelo. Por esto, señala que estas obras deben ser leídas por todas las personas que conocen del dolor y el sufrimiento.

Los griegos no perseguían la intensidad de los estados espirituales, sino su pureza; no adoraban la fuerza sino la verdad, única vía de contacto con lo divino solo posible de conseguir a través de la exactitud y el rigor. La Ilíada narra ese emblemático episodio de la guerra protagonizada por hombres 
sometidos a la fuerza pero, también, ese acontecimiento que se erige como el más puro espejo de integridad frente a la fuerza, en el reconocimiento de la subordinación a ella, en el respeto por la vida expresado en la aceptación de la muerte para sí mismo cuando se inflige a otro ${ }^{12}$. Y, lo más importante, en la Ilíada los combatientes no olvidan que lo más valioso no está enraizado en la existencia ni en esos bienes relativos e híbridos a los que Weil llama metax ${ }^{l 3}$ de la vida terrenal, sino que el alma está proyectada fuera del tiempo, porque lo temporal existe solo como intermediario o metaxu para lo espiritual. De esta manera, dada la inevitabilidad de la guerra, es necesario "humanizarla", lo que en términos weilnianos significaría preservar la pureza del ser humano.

No obstante la excusa del rapto de Helena, la guerra de Troya no se libra de los determinantes de toda guerra y no es ajena a sus condicionamientos, es decir, su naturaleza imperialista de dominio territorial, económico y político y su carácter arrasador y pendenciero, sin objetivo justificable en lo esencial; en otras palabras, para hacer la guerra solo basta la naturaleza humana. El valor del combate para los griegos se medía por el precio que había que pagar: la propia vida y la de los seres amados. Para aqueos y troyanos la palabra mágica que justificaba la guerra era el honor, con nombre de mujer, Helena, que luego fue reemplazada por la evocación de los sufrimientos de los compañeros muertos. En la actualidad esas palabras son reemplazadas por flatus vocis, cuya significación es asignada tendenciosamente para justificar un fin o un medio para el aniquilamiento de los adversarios.

\footnotetext{
${ }^{12}$ Recordemos que Aquiles, el héroe de la guerra de Troya, acepta la muerte propia con tal de alcanzar la gloria y esta significa vengar la muerte de Patroclo, su amigo más querido, matar a Héctor, a costa del cumplimiento de su destino, el que le predijera su madre Tetis: "Por lo que dices, pronto ya, hijo, llegará el destino; pues enseguida después del de Héctor tu hado está dispuesto" (Ilíada, Canto XVIII, v.95-96).

13 Término griego ( $\mu \varepsilon \tau \alpha \xi \dot{v})$, adverbio que significa en medio, en mitad; $\tau \alpha \mu \varepsilon \tau \alpha \xi v$ : intermedio (Diccionario Manual Griego-Español VOX, 1967. Barcelona: Biblograf, p. 390). Se define en el Simposio (Banquete) de Platón a través del personaje de Diotima: "El término metaxú en el Banquete tiene indudablemente un valor sustantivo dado que: a) aparece referido a una entidad: Eros; b) en 202a2 y 202b4 se utiliza la expresión ti metaxú, donde el pronombre indefinido atribuye a lo calificado un indudable carácter sustantivo. Ahora bien, dos razones por las que el amor es calificado en este texto como metaxú responden a los sentidos ya señalados: a) Eros tiene una ubicación espacial intermedia puesto que se encuentra "entre" lo mortal y lo inmortal, "entre" lo humano y lo divino (202d6); b) No es bueno ni malo (202b3-4)" (Martínez y León, 2007a: 253). Weil dice que los metaxus "constituyen el territorio del bien y el mal" (Weil, 1994: 187).
} 
En Troya mediaban los dioses de la mitología griega; en nuestros tiempos se construyen mitos y monstruos expresados en palabras que parecen representar realidades absolutas. Se crean pares antitéticos: comunismofascismo, capitalismo-socialismo, dictadura-democracia. O simplemente se esgrimen "razones" de seguridad, democracia, nación, soberanía o, paradójicamente, de justicia. Todo se absolutiza cuando en realidad atiende a mezquinos intereses particulares y de minorías. El punto de inflexión de este asunto es que los que instrumentan dichos argumentos no son fantasmas, son seres reales que causan destrucción y cadáveres. Es imposible eliminar las guerras mientras existan relaciones de fuerzas variables; por ello, se impone no cejar en la lucha, que según Heráclito es la condición de la vida, pero hay que hacer el ejercicio de discernir lo imaginario, devenido en argumento de lo real. ¿Cuál sería entonces la salida? Tal vez sería, para Weil, aumentar el nivel intelectual mediante una educación que suscite móviles, que favorezca el adiestramiento del animal que llevamos dentro y que facilite la búsqueda del bien ínsito a cada ser humano para conectarse con la pureza y la belleza (Weil, 2007a: 357), porque las guerras no se deciden entre hombres que reflexionan, sino entre hombres caídos en la pasividad (materia inerte) o en el impulso (fuerzas ciegas).

Ahora bien, si la guerra de Troya no se sustrae de la instrumentación humana del horror y de los móviles de la guerra, ¿qué hace a La Ilíada el canto más hermoso e irrepetible sobre la guerra? El hecho de que es una exaltación a la desnudez del alma, sin circunloquios, sin artilugios que disfracen la miseria de la guerra, sin vergüenza de ser todos los personajes doblegados ante la fuerza y lloren humillados por ella. El sometimiento a la fuerza los deja inermes ante el castigo de rigor geométrico, que en Oriente se conoce como karma. Sin discriminación, todos sin excepción sufrirán las consecuencias de la implementación de la fuerza.

La violencia los aplasta a todos y los hermana en miseria y desgracia. Al principio la guerra es un juego, e incluso es amada con bajeza, pero llega la cruda realidad y el descubrimiento de que para su alma, sometida a los rigores de la fuerza, la muerte no es el límite impuesto de antemano al porvenir, sino que es el porvenir mismo, cada día vive esta realidad y cada día el alma sufre violencia y se mutila cualquier aspiración, aún la de poner fin a la guerra, pues el alma piensa que solo puede curarse por la destrucción del enemigo. Homero muestra las transformaciones de los guerreros por medio de símiles que denotan desastres (incendios, terremotos, inundaciones) o la ferocidad 
de las fieras, pero también ilumina el alma de los mismos mediante gloriosos momentos de auto-reflexión, como el de Héctor delante de Troya, o a través de todas las formas de amor por los padres, por los hijos, por la esposa, por el amigo y compañero y, el más excelso, la admiración mutua de los enemigos que se ilustra en las figuras de Príamo y Aquiles.

Este es un canto en el que la amargura procede de la ternura y donde la única verdadera aflicción descansa en la subordinación del alma humana a la fuerza, por lo que todo en el interior de la guerra es fría brutalidad, pero lo demás, lo que atañe al mundo de la paz, aquello que la guerra destruye, está envuelto en poesía. Sin embargo, la máxima grandeza de este poema es el respeto por la miseria de todos los subordinados a la fuerza, pues ninguno es despreciado; por el contrario, es amado dolorosamente a causa del peligro constante de destrucción. Se trata, por tanto, de un reconocimiento constante a lo humano y a lo divino del ser humano, que no se degrada sino que se admira: "Los griegos tuvieron con frecuencia la fortaleza del alma que permite no engañarse; fueron recompensados por ello y supieron alcanzar en todo el grado más alto de lucidez, de pureza y de simplicidad" (Weil, 2007a: 309).

Desde que Grecia fue destruida no quedan más que reflejos de esto. No es difícil creer en la afirmación de Simone Weil: "Algunos crímenes que nos han hecho malditos hemos debido cometer para que hayamos perdido toda la poesía del universo" (Weil, 1994: 183). Cuando el sufrimiento invade al hombre lo obliga a gritar en busca de respuesta; lo hizo Job cuando increpó a Dios, lo hace todo el poema de La Ilíada en el que resuena el grito del sufrimiento, pero no como disonancia, sino como testimonio, como búsqueda de consuelo que no se halla en la explicación del sufrimiento puesto que no existe justificación al mismo, ni tampoco explicación. Al estar en el límite de las facultades humanas, en la medida en que todo está reducido al absurdo, a la impotencia y al vacío, levantamos nuestro desesperado e imperioso ruego; sin embargo, solo nos encontramos con el silencio de Dios, que es inocente del mal del mundo. Entonces, y sin otra opción, tenemos que detenernos en la contemplación porque es el momento de entregar el alma al silencio. He ahí el eminente valor del sufrimiento de los desgraciados y el testimonio del poder de la gracia.

La Ilíada, poema de la fuerza, o mejor, poema iluminado, es entonces un canto al amor y a la compasión ante la debilidad del hombre, una exaltación 
de la capacidad del ser humano para aceptar con bondad y dignidad la fragilidad de su ser, para declinar ante la naturaleza y ante su propia finitud, que no es otra cosa que caer en el imperio de la necesidad, de los deseos de la carne, pero salvaguardando la integridad y la pureza del alma, de aquella que no se ha petrificado por acción de la fuerza bruta. Para Weil, Homero es un iluminado porque entiende y deja clara la sentencia que siglos después, también antes de nuestra era, Tucídides dilucidara acerca de que el hombre está condenado, por necesidad de la naturaleza a dominar donde tiene la posibilidad de hacerlo. Y, para nosotros, Weil es también una iluminada, pues señala igualmente que el poder de la fuerza, aunque vuelva una vez más a suceder en la historia de la humanidad, no por ello es absoluto, porque "por bella que pueda ser la entonación de un grito de dolor, no se puede desear seguir oyéndolo; es más humano desear curar el dolor" (Weil, 1996: 58). ¿O tal vez evadirlo?

\section{Referencias}

Benjamin, W. (2010). Tesis sobre la historia y otros fragmentos. Bogotá: Desde Abajo.

Fichte, J. G. (1984). Primera y segunda introducción a la Teoría de la Ciencia. (Trad. J. Gaos). Madrid: Sarpe.

Heidegger, M. (2008). La pobreza. Buenos Aires: Amorrortu.

Pétrement, S. (2001). La vida de Simone Weil. Madrid: Editorial Trotta.

SloterdiJK, P. (2011). Has de cambiar tu vida. Valencia: Pre-Textos.

Sontag, S. (2008). Contra la interpretación. Buenos Aires: DeBolsillo.

WeIL, S. (2007a). Escritos Históricos y Políticos. Madrid: Editorial Trotta.

WeIL, S. (2007b). Escritos de Londres y últimas cartas. Madrid: Editorial Trotta.

WeIL, S. (2001). Cuadernos. (Trad. C. Ortega). Madrid: Editorial Trotta.

WeIL, S. (1996). Echar raíces. (Trad. J.C. González \& J.R. Capella). Madrid: Editorial Trotta.

WeIL, S. (1994). Gravedad y la Gracia. Madrid: Editorial Trotta.

WeIL, S. (1993). A la espera de Dios. Madrid: Editorial Trotta. 
